\title{
Infected Thrombus of the Bioprosthetic Aortic Valve with Distal Arterial Embolization after 3 Years of Valve Replacement Surgery
}

\author{
Jung Ae Hong, Sung-Ai Kim \\ Division of Cardiology, Hallym University Sacred Heart Hospital, Hallym University College of Medicine, Anyang, Korea
}

\begin{abstract}
Current guidelines recommend the use of warfarin in the first 3 months after bioprosthetic valve replacement and suggest longterm anticoagulation only in patients with obvious risk factors for thrombosis. Despite at low risk of thromboembolism, we present a case of a 72-year-old male patient with infected thrombus at bioprosthetic aortic valve with distal arterial embolization after 3 years of replacement surgery. The incidence of asymptomatic bioprosthetic valve thrombosis (BPVT) may be higher than anticipated and active surveillance echocardiography is needed to early detect BPVT before leading to fatal complication.

Keywords: Infection; Thrombosis; Endocarditis; Bioprosthesis; Aortic valve
\end{abstract}

\section{INTRODUCTION}

The overall rate of biprosthetic valve thrombosis (BPVT) is 0.03\% per year [1] and late valve thrombosis of Mosaic porcine prosthesis is $0.1 \%$ to $0.3 \%$ per patient-year [2,3]. It is a comparatively rare complication, but the sequelae may be fatal. For the antithrombotic therapy of bioprosthetic valve, the American College of Cardiology/ American Heart Association (ACC/AHA) guidelines [4] recommend the use of warfarin for at least 3 months and as long as 6 months after bioprosthetic aortic valve replacement (AVR) and suggest long-term anticoagulation only in patients with obvious risk factors for thrombosis as history of thromboembolism, hypercoagulable conditions, left ventricular dysfunction, and ongoing atrial fibrillation. Herein, we present a case of a 72 -year-old male patient at a low risk of thromboembolism presenting an infected thrombus at bioprosthetic aortic valve (AV) with distal arterial embolization after 3 years of replacement surgery.

\section{CASE REPORT}

A 72-year-old man was admitted to Hallym Sacred Heart Hospital with poor oral intake, fever, and chills for 2 weeks. He had a history of hypertension and had undergone bioprosthetic AVR (23 mm Medtronic Mosaic porcine prosthesis) for degenerative AV stenosis 3 years ago. Postoperatively, the patient was anticoagluated with warfarin for 6 months and has taken aspirin until admission. Physical examination disclosed a grade of $2 / 6$ systolic ejection murmur at the aortic area and a blood pressure of 150/90 $\mathrm{mm} \mathrm{Hg}$, heart rate 95 beats $/ \mathrm{min}$, and a temperature of $38.5^{\circ} \mathrm{C}$. Electrocardiography showed sinus rhythm with right bundle branch block and chest radiography showed no cardiomegaly. Laboratory studies yielded the following results: white blood cell $19.6 \times 10^{3} / \mu \mathrm{L}$ (normal reference range, 4 to $10 \times 10^{3} / \mu \mathrm{L}$ ); hemoglobin $13.8 \mathrm{~g} / \mathrm{dL}$ (normal reference range, 14 to $17 \mathrm{~g} / \mathrm{dL}$ ); platelet $165 \times 10^{3} / \mu \mathrm{L}$ (normal reference range, 130 to $450 \times 10^{3} / \mu \mathrm{L}$ ); C-reactive protein 135 $\mathrm{mg} / \mathrm{L}$ (normal reference range, 0 to $5 \mathrm{mg} / \mathrm{L}$ ); lactate dehydrogenase $674 \mathrm{IU} / \mathrm{L}$ (normal reference range, 240 to $460 \mathrm{IU} / \mathrm{L}$ ); and Btype natriuretic peptide level $256 \mathrm{pg} / \mathrm{mL}$ (normal reference value $\leq 160 \mathrm{pg} / \mathrm{mL}$ ).

Transthoracic echocardiography (TTE) revealed a $1.3 \times 1.4-\mathrm{cm}-$ sized mobile mass attached to bioprosthetic AV (left ventricular side) with an increased transvalvular gradient (max/mean 77/50 $\mathrm{mm} \mathrm{Hg}$ ) (Fig. 1A, B) and a decrease in calculated AV area $0.6 \mathrm{~cm}^{2}$. Transesophageal echocardiography provided no more informa-
Correspondence to: Sung-Ai Kim

Division of Cardiology, Hallym University Sacred Heart Hospital, Hallym University College of Medicine, 22 Gwanpyeong-ro 170beon-gil, Dongan-gu, Anyang 14068, Korea

Tel: +82-31-380-3977, Fax: +82-31-383-3486, E-mail: 237419@hallym.or.kr

Received: Sep. 9, 2015 / Accepted after revision: Sep. 24, 2015
(C) 2015 Soonchunhyang Medical Research Institute This is an Open Access article distributed under the terms of the Creative Commons Attribution Non-Commercial License (http://creativecommons.org/licenses/by-nc/3.0/). 

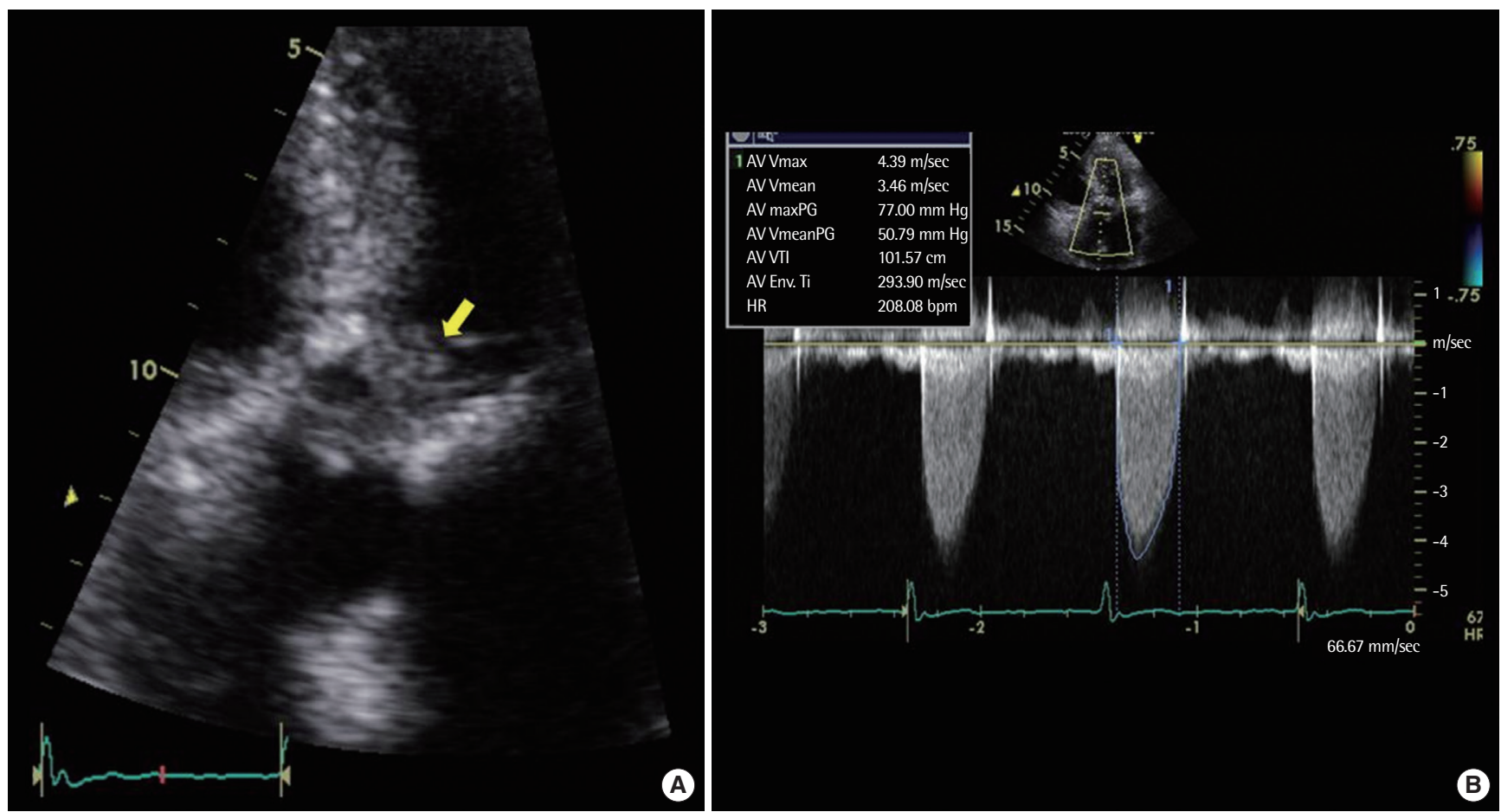

Fig. 1. Transthoracic echocardiography revealed (A) a 1.3×1.4-cm-sized mobile mass (arrow) attached to bioprosthetic aortic valve (left ventricular side) (B) with an increased transvalvular pressure gradient (max/mean $77 / 50 \mathrm{~mm} \mathrm{Hg}$ ). AV, aortic valve; PG, pressure gradient; VTI, velocity time integral; HR, heart rate.

tion than TTE because of acoustic shadowing by struts of bioprosthetic AV. Postoperatively echocardiogram 3 years ago showed a normal functional bioprosthetic AV with a mean transvalvular gradient of $19 \mathrm{~mm} \mathrm{Hg}$ and calculated AV area was $1.8 \mathrm{~cm}^{2}$.

Two of 3 independent peripheral blood cultures drawn during the first 12 hours were positive for a Streptococcus viridans. Under the presumptive diagnosis of infective endocarditis, the patient was initially treated with intravenous ceftriaxone and gentamycin. After 2 weeks, the clinical course was favourable with negative blood cultures and resolution of fever and inflammatory marker (C-reactive protein $6.9 \mathrm{mg} / \mathrm{L}$ ). Nonetheless, follow-up TTE revealed no interval change in size of the mobile mass at bioprosthetic AV. The next day, the patient complained of acute left lower leg pain with a decreased pulse in left dorsalis pedis and the value of ankle-brachial index in left leg was 0.65. Emergent peripheral angiography revealed a total occlusion of trifurcation of left popliteal artery and we successfully performed percutaneous transluminal balloon angioplasty with an intra-arterial injection of urokinase 200,000 unit (Fig. 2A, B). Overall, mobile mass at biprosthetic AV was identified as infected thrombus which caused distal arterial embolization. Because he was hemodynamically stable, we began to anticoagulate with low molecular weight heparin and oral warfarin. After 2
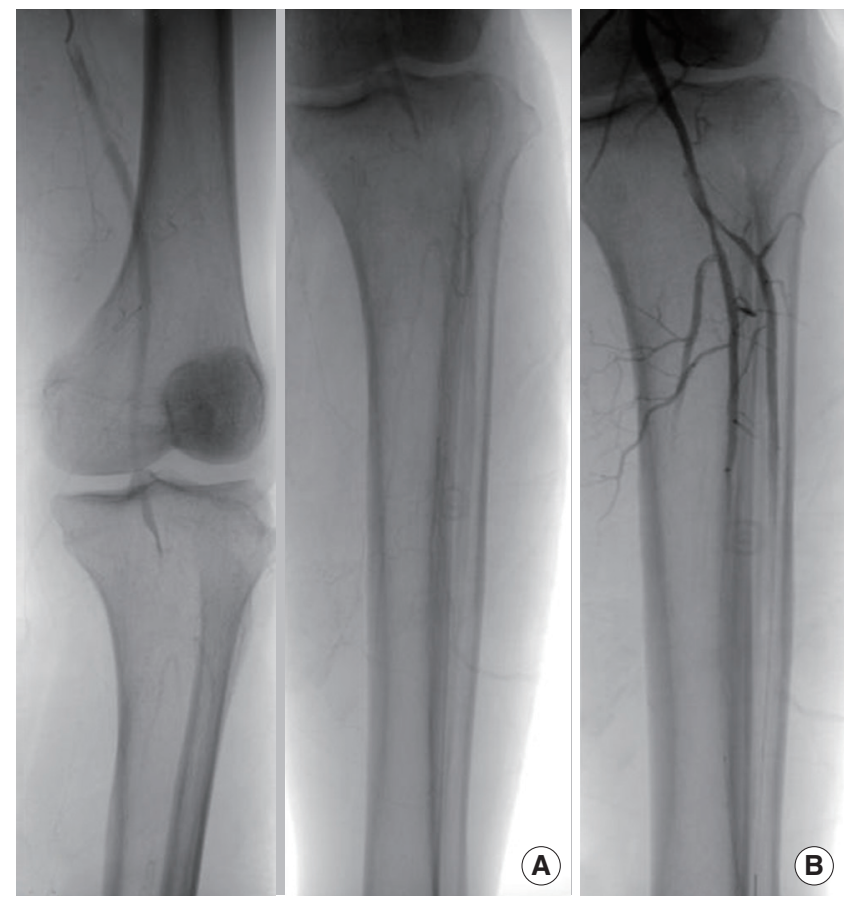

Fig. 2. Peripheral angiography revealed (A) a total occlusion of trifurcation of left popliteal artery and (B) we successfully performed percutaneous transluminal balloon angioplasty with an intra-arterial injection of urokinase 200,000 unit. 

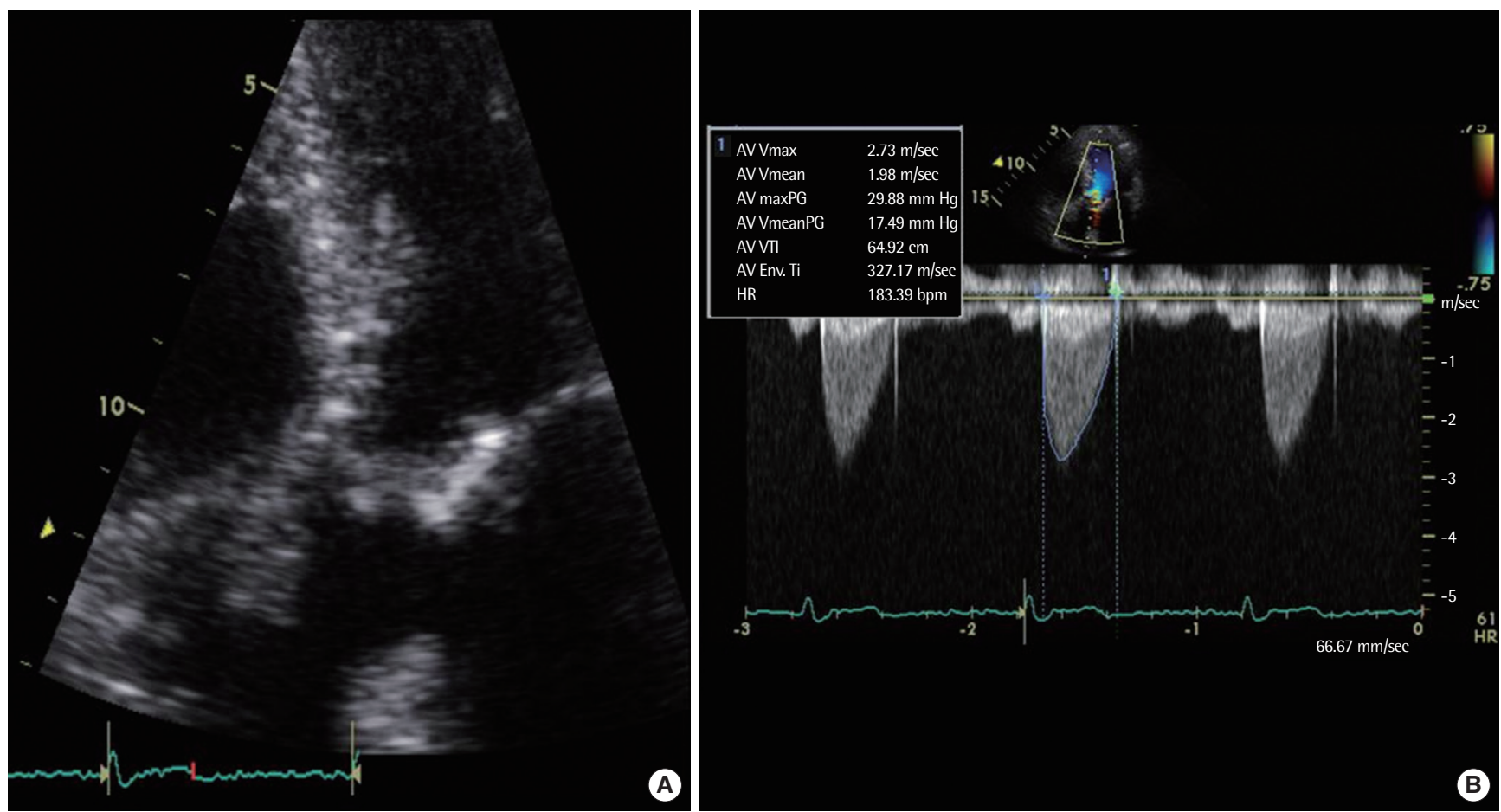

Fig. 3. At fourth week of anticoagulation, (A) follow-up echocardiography showed no more thrombus at bioprosthetic aortic valve and (B) normalization of transvalvular pressure gradient (max/mean 29/17 mm Hg). AV, aortic valve; PG, pressure gradient; VTI, velocity time integral; HR, heart rate.

weeks, the patient was uneventful and follow-up TTE showed a decrease in transvalvular gradient (max/mean, 77/50 to 49/29 mm $\mathrm{Hg})$, although there was no size variation of thrombus $(1.3 \times 1.4$ $\mathrm{cm})$. At fourth week of anticoagulation, follow-up TTE showed no more thrombus and normalization of transvalvular gradient (max/ mean, $49 / 29$ to $29 / 17 \mathrm{~mm} \mathrm{Hg}$ ) and calculated AV area (0.60 to 1.45 $\mathrm{cm}^{2}$ ) (Fig. 3A, B). To summarize, the patient received 2 weeks of double antibiotic therapy followed by 4 weeks of intravenous ceftriaxone and anticoagulation therapy. No bleeding or other adverse events occurred during that period. He was discharged with maintaining oral warfarin and remained asymptomatic for 3 months.

\section{DISCUSSION}

This is the first complicated case of infected thrombus at bioprosthetic AV after 3 years of replacement surgery. Based on the initial presentation, the mobile mass at bioprosthetic AV was regarded as vegetation because of the obvious infection signs and clarifying the mass either vegetation or thrombus with echocardiography was challenging. We were lack of awareness for the coexistence of thrombus until the distal arterial embolization occurred. Despite the absence of histologic confirmation in this case, there is high probability of adhesion of microorganism on the platelet-fibrin obstructive thrombus at bioprosthetic AV with high velocity jet.

Current ACC/AHA and European Society of Cardiology guidelines recommend annual echocardiography beginning 5 years after replacement surgery or when patients become symptomatic or valve dysfunction is suspected [4,5]. However, the occurrence of BPVT in this patient at low risk for thromboembolism and the published cases diagnosed as BPVT on aspirin therapy in which the mean interval of BPVT was 13 months (range, 7 to 47 months) after replacement surgery [6-9], suggest the true incidence of asymptomatic BPVT may be higher than anticipated and stress the necessity of routine annual echocardiography for the first 5 years of post replacement surgery.

The initial standard therapy for left-sided prosthetic valve thrombosis has been surgery or thrombolysis [4]. However, in hemodynamically stable patients, anticoagulation with vitamin $\mathrm{K}$ antagonist (VKA) could be a safe and effective treatment precluding re-do valve operation in patients with obstructive thrombosis at bioprosthetic $\mathrm{AV}[6,9,10]$. In this case, although thrombus is comparatively larger in size $(1.4 \times 1.4 \mathrm{~cm})$, VKA showed sustained improvement of transvalvular gradient and nearly resolution of thrombus for a month, which verified VKA as first-line therapy in 
clinically stable patients with BPVT. Despite of no histologic findings, complete resolution of infection signs and thrombus after antibiotics therapy and anticoagulation confirmed the presence of infective thrombus in this patient. When the mean transvalvular gradient was increased early after valve replacement surgery, differential diagnosis of infective thrombus as well as thrombus and vegetation per se is required with integration of clinical and echocardiographic findings.

\section{REFERENCES}

1. Grunkemeier GL, Rahimtoola SH. Artificial heart valves. Annu Rev Med 1990;41:251-63.

2. Eichinger WB, Botzenhardt F, Gunzinger R, Kemkes BM, Sosnowski A, Maiza D, et al. European experience with the Mosaic bioprosthesis. J Thorac Cardiovasc Surg 2002;124:333-9.

3. Thomson DJ, Jamieson WR, Dumesnil JG, Burgess JJ, Peniston CM, Metras J, et al. Medtronic Mosaic porcine bioprosthesis: midterm investigational trial results. Ann Thorac Surg 2001;71(5 Suppl):S269-72.

4. Nishimura RA, Otto CM, Bonow RO, Carabello BA, Erwin JP 3rd, Guyton RA, et al. 2014 AHA/ACC guideline for the management of patients with valvular heart disease: a report of the American College of Cardiol-
ogy/American Heart Association Task Force on Practice Guidelines. J Thorac Cardiovasc Surg 2014;148:e1-e132.

5. Vahanian A, Alfieri O, Andreotti F, Antunes MJ, Baron-Esquivias G, Baumgartner $\mathrm{H}$, et al. Guidelines on the management of valvular heart disease (version 2012): the Joint Task Force on the Management of Valvular Heart Disease of the European Society of Cardiology (ESC) and the European Association for Cardio-Thoracic Surgery (EACTS). Eur J Cardiothorac Surg 2012;42:S1-44.

6. Jander N, Kienzle RP, Kayser G, Neumann FJ, Gohlke-Baerwolf C, Minners J. Usefulness of phenprocoumon for the treatment of obstructing thrombus in bioprostheses in the aortic valve position. Am J Cardiol 2012;109:257-62.

7. Brown ML, Park SJ, Sundt TM, Schaff HV. Early thrombosis risk in patients with biologic valves in the aortic position. J Thorac Cardiovasc Surg 2012;144:108-11.

8. Efthymiou CA, Mills RJ, O'Regan DJ. Early postoperative thrombosis of an aortic bioprosthetic valve: should anticoagulation be patient specific? J Card Surg 2013;28:723-9.

9. Pislaru SV, Hussain I, Pellikka PA, Maleszewski JJ, Hanna RD, Schaff HV, et al. Misconceptions, diagnostic challenges and treatment opportunities in bioprosthetic valve thrombosis: lessons from a case series. Eur J Cardiothorac Surg 2015;47:725-32.

10. Juliard JM, Paillole C, Dahan M, Steg PG, Himbert D, Aumont MC. Late thrombotic obstruction of an aortic bioprosthetic valve: successful treatment by oral anticoagulation. Clin Cardiol 1993;16:152-4. 